\title{
PRENOSLJIVOST \\ PARTICIPATIVNIH UČNIH METOD V SLOVENSKO OKOLJE
}

Mag. Marjeta Novak

Humus, d. o.o.

\section{POVZETEK}

Po zgledu anglosaških okolij z večdesetletno tradicijo participativnih učnih metod tudi slovenski predavatelji zadnjih petnajst let vse bolj uporabljajo $k$ slušatelju usmerjene dinamične interaktivne pristope $v$ izobraževanju odraslih. Zlasti si tovrstne metode pospešeno utrjujejo pot v poslovnem izobraževanju, kjer se zahtevajo hitri rezultati tako v izobraževanju kot pri prenosu znanj in vešcin y vsakdanjo prakso. Vendar pa marsikateri predavatelj pri implementiranju participativnih metod naleti na odpor slušateljev, ki korenini v specifičnih družbenoekonomskih razmerah slovenskega kulturnega okolja. Prispevek skuša osvetliti nekatere kritične točke pri uporabi participativnih metod ter prikazati dobre prakse, kako se izogniti najpogostejšim napakam.

Ključne besede: participativne metode, interakcija, medkulturne razlike, poslovno izobraževanje

anašnje poslovno okolje zaradi vse večje kompleksnosti in dinamičnosti zahteva samoiniciativne, odzivne in kompetentne zaposlene, ki znajo samostojno reševati probleme. Odzivati se je potrebno hitro in kakovostno, za čakanje navodil od zgoraj navzdol enostavno ni več časa. Za tako delovanje pa je potrebna temeljita sprememba $v$ miselnosti, kar še zlasti velja za tista družbenoekonomska okolja, ki s(m)o še vedno v tranziciji - prejšnji režim je razpadel, novi pa šele lovi korak z globaliziranim poslovnim okoljem.

$\checkmark$ globalni konkurenci bodo preživeli le tisti, ki bodo izkoristili čim večji potencial zaposlenih. V Evropi to že dolgo ni več fizično delo, pač pa intelektualni, socialni in drugi kapitali.
Tem sprememban $v$ koriščenju človeških potencialov se pospešeno prilagajajo tudi izobraževanja in usposabljanja za razvijanje kompetenc zaposlenih v podjetjih in organizacijah, zlasti na področju »mehkih« veščin - vodenja, komuniciranja, timskega sodelovanja itn.

Po ameriških vzorih postajajo učni dogodki vse bolj interaktivni: vedno več je akcije, učenja skozi izkušnjo, skupinPodjetja ne išcejo vec fizičnega dela, temveč intelektualni, socialni, emocionalni in duhorni kapital. skega dela, simulacij, študij primerov, iger vlog, reševanja konkretnih problemov. Pri tem pa marsikateri slovenski predavatelj v želji, da bi naredil učni dogodek 
čimbolj zanimiv, trči ob nevidno pregrado - odziv slušateljev je medel in nezaupljiv, na evalvacijskih vprašalnikih ob koncu dneva pa prebere: »To so bile igrice, ne pa učenje.«

Namen tega prispevka je osvetliti nekatere kritične točke, ki čakajo nadebudnega predavatelja pri prenašanju anglosaških participativnih učnih pristopov $v$ slovensko kulturno okolje izobraževanja odraslih.

Ko pride povprečni slovenski zaposleni na izobraževanje za razvijanje »mehkih« veščin, njegova motivacija za učenje ponavadi ni na višku. Zavira jo že dejstvo, da je na izobraževanje poslan »od zgoraj«, kar si interpretira, da je z njim nekaj narobe in da

Stare šlske

prakse so glavna ovira za večjo interaktivnost vizobraževanju odraslih.

je treba »popraviti«. Vodje se večinoma v isto izobraževanje ne vključijo, s čimer dajejo podrejenim signal, da oni teh izobraževanj ne potrebujejo ter da so »nekaj več od njih «.

Poleg tega kazenskega dojemanja svoje prisotnosti se pri povprečnem udeležencu izobraževalnega dogodka že ob vstopu v predavalnico vzbudijo vse asociacije na leta formalnega šolanja zlasti tiste najbolj negativne. Udeleženec se spomni, kako je bil vsa leta šolanja v izrazito podrejenem položaju v primerjavi z učiteljem.

Le-ta mu je predajal svete

Kulturne razlike ne dopuščjo neposrednega prenosa ucnih metod in pristopov $v$ drugo kulturno okolje. resnice in ni trpel nikakršnih drugačnih mnenj in pogledov. Cenjena je bila predvsem ubogljivost. Misliti s svojo glavo je bilo nezaželeno - veliko pomembneje je imeti lepo urejene zvezke. Reševanje problemov? Kje pa, to je preveč neakademsko. Pomembno pa je znati na pamet goro nerazumljivih besed, ki bodo ušle iz spomina takoj po zaključenem trimestru.

Predvsem pa učitelj ni nudil podpore pri raz- vijanju potencialov otrok, pač pa je bil neutrudni iskalec neznanja. Med spraševanjem pred tablo se je »zbudil« šele takrat, ko je učenčevo deklamiranje naučenega na pamet zastalo. Znanjc, kot ga je dolgočasilo, napake in neznanje pa poživilo. Ko je pregledoval domače naloge, je vpisoval samo minuse; plusi niso šteli nič. V okolju, ki išče neznanje, ne pa znanja, je težko razviti pozitiven odnos do učiteljev.

Povprečni učenec se je naučil in kmalu pozabil mnoge podatke; ni pa pozabil naslednjih lekcij, ki jih je v njem pustilo dolgoletno dresiranje:

- Učenje je trpljenje.

- Nikoli ne izzivaj avtoritete.

- Red in disciplina nad vse.

- Učenci in učitelji stojijo na dveh različnih bregovih.

- Ko mačke ni doma, miši plešejo ...

Te lekcije, zakoreninjene globoko $\mathrm{v}$ posameznikovi psihi, še danes vplivajo na odnos do izobraževalnih dogodkov in seveda na odnos do predavatelja, ki pooseblja učiteljsko avtoriteto.

\section{MEDKULTTURNE RAZLIKE}

Povprečni ameriški (pa tudi angleški, skandinavski, nizozemski ...) zaposleni ima za seboj drugačno izkušnjo $\mathrm{z}$ učitelji: le-ti so spodbujali diskusijo in različna mnenja, niso pridigali dokončnih dogovorov, učence so spodbujali k timskemu reševanju problemov. $\mathrm{V}$ učilnici ni bilo tihe strahovlade, pač pa je učitelj moral avtoriteto zgraditi s pristopi, ki motivirajo mlade za sodelovanje. Ko pride tak bivši učenec - sedaj odrasli - na poslovno izobraževanje, je že v štartu zdravo radoveden in poln pozitivnih pričakovanj.

$\mathrm{V}$ zadnjih petdesetih letih je močno napredovalo preučevanje medkulturnih razlik. Izluščenih je bilo kar nekaj ključnih dimenzij, po katerih se kulture razlikujejo med seboj, med njimi pa so za naše razmišljanje najbolj 
ZDA so po mnogih raziskavah (Trompenaars in Hampden-Turner, 1997; House in drugi, 2004; Hofstede in Hofstede, 2005) najbolj individualistična kultura med vsemi do sedaj raziskanimi. $\mathrm{V}$ javnem delovanju se ceni samozavest in suverenost, neposredno izražanje svojih mnenj in individualnih potreb, konflikti so naravni del interakcije, spodbuja se kultivirano soočanje različnih pogledov.

relevantne tri, ki nam pomagajo osvetliti razlike v odnosu do participativnih učnih metod med kulturnimi okolji Slovenije in ZDA.

$V$ bolj kolektivističnih okoljih pa ljudje težijo k ohranjanju brezkonfliktnih odnosov, kar pomeni, da drugačna mnenja niso zažclena, saj rušijo navidezno harmonijo v skupini. Cenita se skromnost in prilagajanje večini.

Drugič, ZDA so v primerjavi s Slovenijo bolj egalitarna kultura od slovenske. V egalitarnih kulturnih okoljih je cilj starševske vzgoje otroke narediti čimprej samostojne in neodvisne. $V$ hierarhičnih kulturah pa otroke od zgodnjega otroštva naprej učijo ubogljivosti, pridnosti in spoštovanja avtoritet. Vzorec se nadaljuje tudi $v$ šoli in na delovnem mestu: $v$ egalitarnih kulturah so ljudje $v$ temelju enakovredna človeška bitja, ki $v$ različnih organizacijah (šola, služba) sicer prevzemajo različne funkcije. Komunikacija med njimi je lahko enakovredna ne glede na status - sploh $v$ primerjavi z bolj hierarhičnimi kulturami, kjer je komunikacija med ljudmi različnega statusa bolj otežena in formalizirana.

Tretjič, mesto nadzora je pri povprečnem Američanu veliko bolj $v$ njem kot pri Slovencu. Slovanske kulture tipično spadajo med t. i. »fatalistične« kulture (Storti, 1999), v katerih ljudje, soočeni s problemom, veliko časa in energije namenijo pogledu nazaj, iskanju krivcev in rekreativnemu jamranju, $\mathrm{k}$ aktivnemu reševanju problema pa pristopijo šele, ko so izčrpane vse druge možnosti. Za kulture notranjega nadzora, kamor $v$ prvi vrsti sodijo ZDA, pa je značilno mnenje, da človek s svojo voljo, z odločnostjo, znanjem in viri lahko vpliva na zunanje okoliščine in je v visoki meri odgovoren za svoj status.

\section{AMERIŠKI POGLED NA SVET}

Participativne metode so nastale $v$ kulturnem okolju ZDA, ki se od slovenskega močno razlikuje. Ameriški pogled na svet (worldview) odlično ilustrirajo temeljne predpostavke: »Prepričanja, ki so tako globoko ukoreninjena v neki kulturi, da se jih redko poimenuje, nikoli ne postavljajo pod vprašaj, pripadnik kulture pa je zelo presenečen, če je postavljen

Za ameriško kulturo so značilne naslednje temeljne predpostavke (prav tam, str. 40):

- Človek ima nadzor nad svojim življenjem in okoljem, zaradi česar je potrebno zavreči idejo usodnosti.

- Spremembe so neizbežne in zaželene.

- Družbeni ideal je enakost in egalitarizem.

- Posameznik je pomembnejši od skupine.

- Samopomoč je boljša od odvisnosti od drugih.

- Tekmovalnost in liberalno podjetništvo sta najboljša za gospodarski razvoj.

- Prihodnost je pomembnejša od preteklosti.

- Akcija je boljša kot kontemplacija.

- V socialnih interakcijah je zaželena neformalnost.

- Direktnost in odprtost sta vrlini.

- Praktični vidiki imajo prednost pred abstraktnim, ideali ali intelektualnim.

- Izboljševanje materialnih razmer koristi človeku bolj kot njegov duhovni razvoj.

- Reševanje problemov je najboljši pristop za obvladovanje realnosti.

- Logika vzroka in posledice nam pomaga dojeti smisel človekovega obstoja. 
v položaj, ko mora te predpostavke braniti. Participativne metode so nastale $v$ kulturnem okolju ZDA

Te predpostavke ljudje v neki kulturi doživljajo kot danosti, s katerimi bi se strinjal vsak inteligenten, kultiviran človek kjerkoli po svetu« (Kohls in Knight, 1994, str. 39)
Marsikatera, če ne kar večina temeljnih ameriških predpostavk je za Slovence zelo problematična.

\section{IZZIVI ZA SLOVENSKE PREDAVATELJE}

Izhajajoč iz temeljnih ameriških predpostavk lahko zaključimo, da ameriški predavatelj pri vodenju seminarja lahko racuna na proaktivnost, pozitiven odnos do sprememb, enakopravno sodelovanje, odprtost, neformalnost, ki so predpogoji za uspešno participativno sodelovanje.

Slovenski predavatelj pa bo moral dodatno streti več trdih orehov; na tcm mestu predstavljamo tri, ki se nam zdijo najbolj ključni:

- kako vzbuditi zaupanje;

- kako pridobiti sodelovanje vseh;

- kako uravnotežiti predavateljsko poučevanje in interaktivno delo udeležencev.

\section{VZPOSTAVLIANJE ZALIPANJA}

Zaupanje je zlasti problematično zato, ker udeleženci v predavatelja na začetku marsikdaj projicirajo vse slabe izkušnje $z$ učitelji in drugimi avtoritetami iz njegovega dotedanjega življenja. Zato je pomembno, da predavatclj na začetku zavestno in proaktivno sestopi s prestola »nedotakljive« figure skoraj boga in se postavi na isto hierarhično raven s svojimi slušatelji, ki sedaj niso več nebogljeni otroci, pač pa polnopravni odrasli.

To lahko stori npr. tako, da na začetku:

- pojasni, da bo z njimi delil predvsem svoje izkušnje, ki si jih je nabral pri opazovanju mnogih delovnih okolij in skupin;
- ve, da so si kot kompetentni odrasli nabrali ogromno lastnih izkušenj in znanj, zato naj jih aktivno prispevajo.

Vsakršna arogantnost je $v$ odnosu do slušateljev popolnoma neumestna.

Seveda so poleg tega pomembne vse druge klasične prvine izgradnje zaupanja, kot so obvladanje tematike, avtentičnost, prepričljive reference, umirjen in suveren nastop ter odprtost za potrebe slušateljev.

$\mathrm{Z}$ odprtim, participativnim, enakovrednim pristopom predavatelj začne ustvarjati spodbudno učno okolje, $v$ katerem se bodo slušatelji lahko počutili dovolj varne, da bodo aktivno sodelovali.

\section{VKLJUČITI VSE PRISOTNE}

Zaradi družbenoekonomskih in kulturnih razlik ter zaradi negativne izkušnje skozi obvezno šolanje so slovenski slušatelji $\mathrm{v}$ povprečju precej manj pripravljeni izpostaviti se s svojimi mnenji, vprašanji, izkušnjami pred celotno skupino oz. y javnosti na splošno. Strah, da bi se kakorkoli osramotili, je prevelik, slabe izkušnje iz šolskega okolja pa še premočno vtisnjene $\mathrm{v}$ spomin. Na predavateljevo povabilo, ali imajo kakšno vprašanje, je tišina zelo pogost odziv. V anglosaških okoljih je odziv veliko večji: dvigne se kar precej rok, predavateljeva naloga je le, da pozornost uravnoteženo porazdeli med čim več spraševalcev. V Sloveniji je slušatelje potrebno najprej spodbuditi, da sodelujejo.

Eno od orodij, ki pomagajo soustvarjati varen komunikacijski prostor, je skupno oblikovanje komunikacijskih »pravil igre «: udeleženci individualno zapišejo ključna konkretna komunikacijska vodila, ki pripomorejo k učinkoviti komunikaciji v skupini. Predavatelj jih zapišc na tablo flipchart, nato pa skupina (npr. z glasovanjem s pikicami) izbere tista, ki se zdijo najpomembnejša. Pomembno je, da se $\mathrm{z}$ izbranimi »pravili igre « strinjajo prav vsi prisotni; če se ne, jih je treba korigirati oz. prilagoditi in ta postopek ponavljati vse 


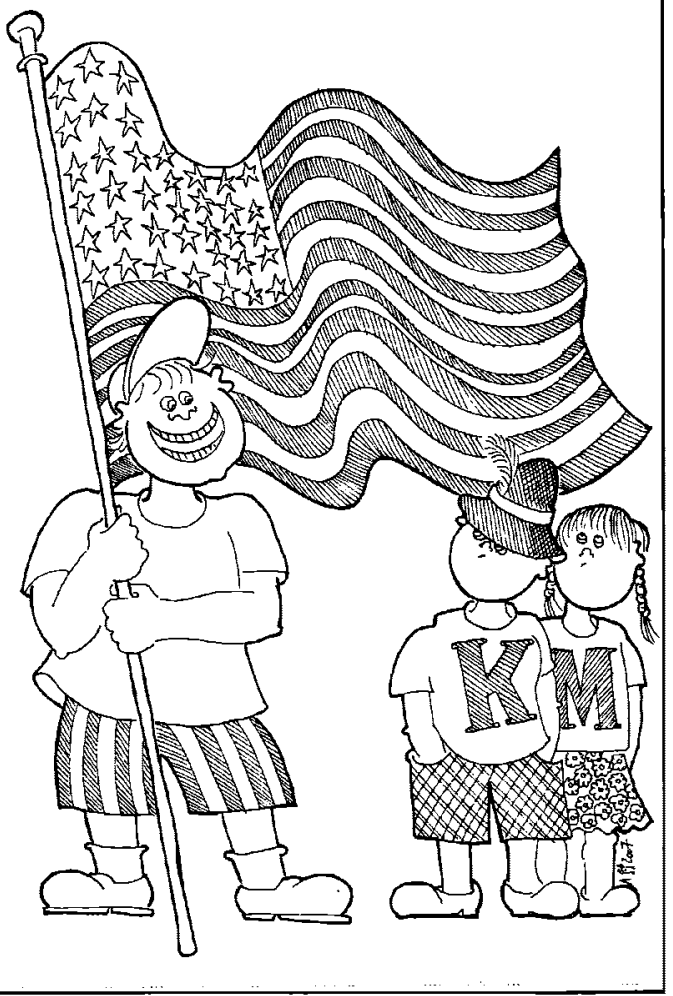

na predstavi svoje ugotovitve veliki skupi-

i. Za optimiziranje porabe časa je zaželeno,

$\exists$ imajo skupine različne zive, vsi pa lahko na koncu ispevajo še dodatne uvide in kušnje.

'elo v majhnih skupinah še ¿ pomeni, da smo res prido-

Slovenci smo na izobraževanjih komunikacijsko zelo zadržani. li sodelovanje vseh. Eden ajvečjih problemov, na katere naletimo pri ovenskih skupinah, je prevlada dominantih govorcev nad ostalimi. Potem ko je preavatelj vložil veliko energije $v$ spodbujanje 
udeležencev k sodelovanju, se prerado zgodi, da si dominantneži prilastijo čas in prostor za diskusijo, bolj tihi posamezniki, ki imajo sicer marsikaj povedati, a se $v$ takih razmerah ne počutijo dovolj motivirani, pa molčijo. Za premoščanje teh ovir odlično služijo tehnika »beseda kroži« in klasični moderatorski pripomočki, kot so barvni kartoni velikosti približno 20 krat 10 centimetrov. Kadarkoli si želimo prispevkov prav vseh, kartončke razdelimo med udeležence in jih povabimo, da na vsak kartonček zapišejo idejo oz. vprašanja, idealno s flomastri za pisanje po tablah fipchart. Nato povabimo vsakogar, da skupini predstavi po eno idejo in le-to zabeležimo $\mathrm{v}$ »skupinski spomin«, denimo na flipchart. Po potrebi naredimo več krogov, dokler se vse ideje ne izčrpajo.

Pozitivna posledica šolskega sistema, ki je poudarjal ubogljivost, je za predavatelja $v$ tem, da slušatelii večinoma brez prehudih pomislekov sledijo predavateljevim izzivom oz. nalogam - seveda vse dotlej, ko se ni treba izpostaviti pred drugimi. Negativna posledica šolskega sistema pa je, da sploh pri zahtevnejših nalogah $\vee$ majhnih skupinah člani radi zaidejo s poti, še zlasti, če predavatelj nima časa in virov, da bi pozorno spremljal prav vsako majhno skupino. Tipičen primer je igra vlog. Ker je zaigrana situacija morda neprijetna (npr. izražanje kritike), udeleženci $\mathrm{z}$ aktivnostjo zelo pohitijo ali pa začnejo komentirati, kaj se da in kaj ne, kdo je kriv in dolžan ... skratka, ne sledijo algoritmu oz. orodju, ki naj bi ga vadili. Podobno je pri

Kje je meja med predavanji in participativnostjo? nalogah reševanja konkretnih problemov: Slovenci zelo radi $\mathrm{v}$ neskončnost ugotavljamo krivce za nazaj in naprej, zelo dolgo pa traja, da se usmerimo $\mathrm{k}$ proaktivnemu iskanju konkretnih korakov, kako naprej.

Predavatelj si $v$ teh situacijah lahko pomaga $s$ »šolsko izkušnjo《: enostavno vključi elemente nadzora. Igre vlog so lahko uspešne le, če je vključen vsaj en opazovalec ali raje dva, pri čemer morata oba slediti jasnim navodilom, kaj natančno naj spremljata in ocenjujeta. Preden pa podata svojo »sodbo«, naj dobijo besedo sodelujoči v igri vlog. Pomembno je, da imajo priložnost najprej sami povedati, kaj bi lahko naredili bolje in s tem vsaj delno ohranijo svoje dostojanstvo. Drugi možni elementi nadzora so lahko npr. predstavitev individualnih akcijskih načrtov pred vso skupino, testi takoj po izobraževanju, preverjanje prenosa $v$ prakso po pretečenem času, npr. treh mesecev, kontrolna ponovna srečanja ipd.

Pri reševanju problemov je zaželeno, da ima predavatelj po potrebi somoderatorje, ki usmerjajo proces proti želenim ciljem $-\mathrm{s}$ tem se izognemo preveč posplošenim rezultatom v slogu »izboljšati je treba komunikacijo«, namesto »od naslednjega meseca naprej uvajamo redne sestanke vsak petek ob osmih, z vnaprej sporočenim dnevnim redom itn.«.

\section{RAVNOTEŽJE MED PREDAVANII IN INTERAKTIVNOSTJO}

V slovenskih delovnih okoljih slušatelji v veliki meri še vedno pričakujejo recepte, rešitve, navodila, algoritme ..., ki jih predavateljska avtoriteta podeli prisotnim. $\breve{C}$ e je interaktivnega dela, $t j$. prebujanja in plemenitenja tihega znanja $v$ skupini preveč, bodo domov šli z občutkom, da se niso naučili skoraj nič novega. Naročnik izobraževanja je denar tako rekoč vrgel stran. Trend izobraževanj sicer gre $\mathrm{v}$ smeri večje participativnosti, ključno $v$ sedanji fazi pa je ubrati pravo ravnotežje med predavateljskimi vložki in akcijo udeležencev.

Prvo vodilo naj bo, da pozornost po $25 \mathrm{minu}$ tah poslušanja močno upade - zato naj bodo predavanja »ex cathedra « približno tolikšne dolžine. Nato pa naj se pasivnost slušateljev prekine $\mathrm{z}$ njihovimi bodisi individualnimi ali 
skupinskimi aktivnostmi.

Drugo vodilo se nanaša na izbiro interaktivnih metod. V strokovni literaturi najdemo na tisoče metod za zelo različne namene, vendar izbira ni tako enostavna. Najprej si mora predavatelj razjasniti, katere cilje želi $\mathrm{z}$ interaktivno metodo doseči. Metoda mora zelo transparentno in zelo učinkovito demonstrirati ali povzeti učna spoznanja. Če je relevantnost le približna, bodo slušatelji ostali nezadovoljeni - zdelo se jim bo, da je čas vržen stran.

Seveda je pri izbiri treba upoštevati še vse druge dejavnike: čas, prostor, material, vpetost v dramaturgijo izobraževalnega dogodka, žongliranje $z$ različnimi pristopi za različne inteligentnosti in učne tipe. Potrebna je res temeljita strokovna presoja, kako izbrati tako aktivnost, ki bo udeležence dejansko motivirala, in kje bo učni izkoristek tako velik in transparenten, da bo zadovoljil tudi izrazite skeptike. Sicer se je bolje zateči h klasičnim predavateljskim pristopom.

Zelo pomembna pa je tudi medkulturna optika: kako se bo izbrana metoda "prijela« $v$ pregovorno sramežljivem slovenskem okolju. Marsikatera zagrevalna aktivnost, npr. t. i. ledolomilec, je $v$ Sloveniji bolj snežni top kot kaj drugega. Številne aktivnosti, ki se zdijo neformalnim Američanom nadvse zabavne in od njih ne pričakujejo posebnih uěnih poant, se Slovencem kaj hitro zazdijo neumne in jih dojemajo kot čisto zapravljanje časa. Naj spomnimo - učenje je v slovenskih šolah trdo delo, ne pa zabava. Ledolomilci so med najbolj delikatnimi aktivnostmi - če se predavatelju zalomi $z$ izbiro aktivnosti že na začetku, bo potem še v hujši situaciji, kot je bil na začetku.

Za doseganje učnega cilja je $v$ slovenskih okoljih (še veliko bolj kot $v$ primerljivih ameriških) pozornost potrebno posvetiti uvodu $v$ aktivnost: kaj bomo počeli in zakaj ter kakšna je njena učna vrednost. Še pomembnejša pa je rekapitulacija po sami aktivnosti: kaj smo se naučili, katera nova vprašanja in dileme se odpirajo za naprej ter zlasti, kako bomo usvojena spoznanja prenesli $\mathrm{v}$ vsakdanjo prakso. Element prenosa $v$ prakso je pri fatalističnih kulturah trši oreh kot pri proaktivnih, kakršna je kultura $\mathrm{ZDA}$, zato mu je potrebno Ličenje je trdo delo, toda naj bo tudi zabava - tako bodo rezultati večji.

posvetiti več časa in mu zagotoviti ustrezno platformo, skozi katero se bo uresničil.

\section{ZAKLIUČNE MISLI}

Interaktivne metode učenja v veliki meri slušateljem omogočajo izpopolnjevanje tistih za delo pomembnih praktičnih znanj in veščin, ki jih formalni šolski sistem večinoma zapostavlja. V kompleksnem poslovnem okolju pa postajajo vse pomembnejše, zato se bo trend takih izobraževanj in usposabljanj samo še stopnjeval. Vendarle pa je za optimalno doseganje učnih ciljev interaktivne metode potrebnoprilagoditi slovenski komunikacijski kulturi - avtomatično prenašanje ameriških in drugih anglosaških pristopov se lahko izkaže za kontraproduktivno. Ker povprečen slovenski slušatelj učenje še vedno sprejema kot »težaško delo«, mu je potrebno ponuditi vrsto učnih izzivov - od individualnih do skupinskih, intelektualnih in izkušenjskih, ki se morajo vsi jasno navezovati na zastavljene učne cilje, ne pa biti sami sebi namen.

\section{LITERATURA}

Adler, N. J. (2002). International Dimensions of Organizational Behavior. Cincinatti: South Western.

Eitington, J. E. (2002). The Winning Trainer. Woburn: Butterworth-Heinemann.

Hall, E. (1976). Beyond Culture. New York: Anchor Books.

Hall, E. (1973). The Silent Language, New York: Anchor Books.

Hofstede, G. (2001). Culture's Consequences: Comparing Values, Behaviors, Institutions and Organizations accross Nations (2. izd.). Thousand Oaks: Sage. 
Hofstede, G., Hofstede, G. J. (2005). Cultures and Organisations - Software of the Mind. New York: Mc Graw Hill.

House, R. J., Hanges, P. J., Javidan, M., Dorfman, P. W., Gupta, V. (ur.) (2004). Culture, Leadership, and Organizations. Thousand Oaks: Sage.

Kohls, L. R., in Knight, J. M. (1994). Developing intercultural awareness. Yarmouth; Intercultural Press.

Lewis, R. D. (1999). When Cultures Collide. London: Nicholas Brealey.

Storti, C. (1999). Figuring foreigners out. London: Nicholas Brealey.

Trompenaars, F., Hampden-Turner, C. (1997). Riding the Waves of Culture: Understanding Diversity in Global Business. London: Nicholas Brealey. 